\title{
Mimosoideae (Leguminosae) Nos CAMPos RUPESTRES do Parque Estadual do Itacolomi, Minas Gerais, Brasil ${ }^{1}$
}

\author{
Valquíria Ferreira Dutra ${ }^{2,4}$, Flávia Cristina Pinto Garcia ${ }^{2}$ \\ \& Haroldo Cavalcante de Lima
}

\begin{abstract}
Resumo
(Mimosoideae (Leguminosae) nos campos rupestres do Parque Estadual do Itacolomi, Minas Gerais, Brasil) Este trabalho trata do estudo taxonômico das espécies de Mimosoideae encontradas nos campos rupestres do Parque Estadual do Itacolomi (PEI), situado no sul da Cadeia do Espinhaço. As coletas foram mensais, no período compreendido entre setembro de 2003 e outubro de 2004, em oito trilhas preestabelecidas. Foram encontradas 11 espécies de Mimosoideae, reunidas em três gêneros: Abarema (1 sp.), Inga (2 spp.) e Mimosa (8 spp.). São apresentadas chaves, descrições e ilustrações para as espécies. Além disso, são fornecidos dados sobre a distribuição geográfica, fenologia, taxonomia e hábitat das espécies estudadas.
\end{abstract}

Palavras-chave: Cadeia do Espinhaço, flora, Abarema, Mimosa, Inga. Mimosaceae, Fabaceae.

\section{Abstract}

(Mimosoideae (Leguminosae) in the "campos rupestres" of the Itacolomi State Park, Minas Gerais, Brasil) A taxonomic treatment of the species of Mimosoideae from "campos rupestres" of the Itacolomi State Park (PEI), south portion of Espinhaço Range, is presented. Field trips were performed monthly, from September/ 2003 to October/2004, in eight pre-established trails. Eleven species of Mimosoideae were found, belonging to three genera: Abarema (1 sp.), Inga (2 spp.) and Mimosa ( 8 spp.). An analytic key, species diagnoses and illustrations are presented. Additional informations are providing concerning geographic distribution, phenology, taxonomy and habitats.

Key words: Espinhaço Range, flora, Abarema, Mimosa, Inga. Mimosaceae, Fabaceae.

\section{INTRODUÇÃo}

Os campos rupestres ocupam as cotas mais altas da Cadeia do Espinhaço, que compreende um conjunto de serras entre os limites $20^{\circ} 35^{\prime} \mathrm{e}$ $11^{\circ} 11^{\prime} \mathrm{S}$, desde a Serra de Ouro Branco, Minas Gerais, até a Chapada Diamantina, Bahia (Giulietti et al. 1997). Também ocorrem como ilhas florísticas isoladas, em Goiás, no Distrito Federal, na porção sudoeste e sul de Minas Gerais (Romero 2002), em Roraima (Benites et al. 2003), na Chapada dos Parecis, em Rondônia (Harley 1995) e na Serra do Cachimbo, no Pará (Pires \& Prance 1985).

O Parque Estadual do Itacolomi (PEI) localiza-se no limite sul da Cadeia do Espinhaço, nos municípios de Ouro Preto e Mariana, ocupando uma área de aproximadamente 7.000 ha (Peron 1989). A vegetação é composta por floresta estacional semidecidual e pelos campos rupestres, que abrangem toda a área acima da cota de 900 m (Messias et al. 1997).

Leguminosae é uma das famílias mais diversas nos campos rupestres, com cerca de 343 espécies e 50 gêneros (Dutra et al. 2008a). É a terceira maior família de Angiospermae, com aproximadamente 727 gêneros e 19.325 espécies, subordinadas a três subfamílias: Caesalpinioideae, Papilionoideae e Mimosoideae (Lewis et al. 2005).

Mimosoideae apresenta cerca de 3.270 espécies agrupadas em 82 gêneros, distribuídos nas regiões tropicais e subtropicais com diversos gêneros ocorrendo também em regiões temperadas (Elias 1981; Lewis et al. 2005). Barroso et al. (1991) citam, para o Brasil, 580 espécies nativas agrupadas em 26 gêneros. Nos campos rupestres compreende 10 gêneros e 86

\footnotetext{
Artigo recebido em 11/2007. Aceito para publicação em 05/2008.

${ }^{1}$ Parte da Dissertação de Mestrado da primeira autora. Curso de Pós-Graduação em Botânica, Universidade Federal de Viçosa, MG, Brasil

${ }^{2}$ Departamento de Biologia Vegetal, Universidade Federal de Viçosa, 36570-000, Viçosa, MG, Brasil.

${ }^{3}$ Instituto de Pesquisas Jardim Botânico do Rio de Janeiro, R. Pacheco Leão 915, 22460-030, Rio de Janeiro, RJ, Brasil

${ }^{4}$ Autora para correspondência: valquiria.dutra@bol.com.br
} 
espécies (Dutra et al. 2008a). Caracteriza-se pelas folhas bipinadas, exceto em Inga; flores actinomorfas, 3-7-meras; cálice gamossépalo, com prefloração valvar no botão; frutos deiscentes, sendo os tipos mais frequientes os folículos e os legumes, ou indeiscentes, como os legumes bacóides, nucóides e samaróides; sementes com hilo diminuto, com ou sem um pleurograma distinto; embrião com eixo radículahipocótilo reto (Bentham 1876; Barroso et al. 1999; Doyle et al. 2000).

Poucos trabalhos foram publicados sobre a subfamília em Minas Gerais: Nunes (2003) listou, para o Parque Estadual do Rio Doce, 33 espécies, reunidas em 14 gêneros; Queiroz (2004) reconheceu 10 gêneros e 25 espécies, em Grão Mogol; Lima et al. (2007) levantaram 30 espécies e 20 gêneros para as florestas estacionais do Parque Estadual do Itacolomi; e Dutra et al. (2008) identificaram na Serra de Ouro Branco, quatro espécies e dois gêneros.
Este trabalho teve como objetivo contribuir para o conhecimento de Leguminosae da flora dos campos rupestres e de Minas Gerais, através do inventário florístico e do estudo taxonômico das Mimosoideae dos campos rupestres do PEI, com a apresentação de chaves, descrições dos táxons encontrados na área, ilustrações, comentários sobre a taxonomia, a distribuição geográfica e a fenologia dos mesmos.

\section{Material e Métodos}

O Parque Estadual do Itacolomi (PEI) situa-se entre as coordenadas $20^{\circ} 22^{\prime} 30^{\prime \prime}$ -

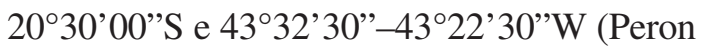
1989), nos municípios de Ouro Preto e Mariana, Minas Gerais (Fig. 1a). Ocupa a zona de transição entre a mata atlântica e o cerrado (Messias et al. 1997) e a vegetação que recobre a maior parte de sua área pode ser classificada como campo rupestre, que ocorre em altitudes superiores a $900 \mathrm{~m}$, podendo ser identificados seis tipos
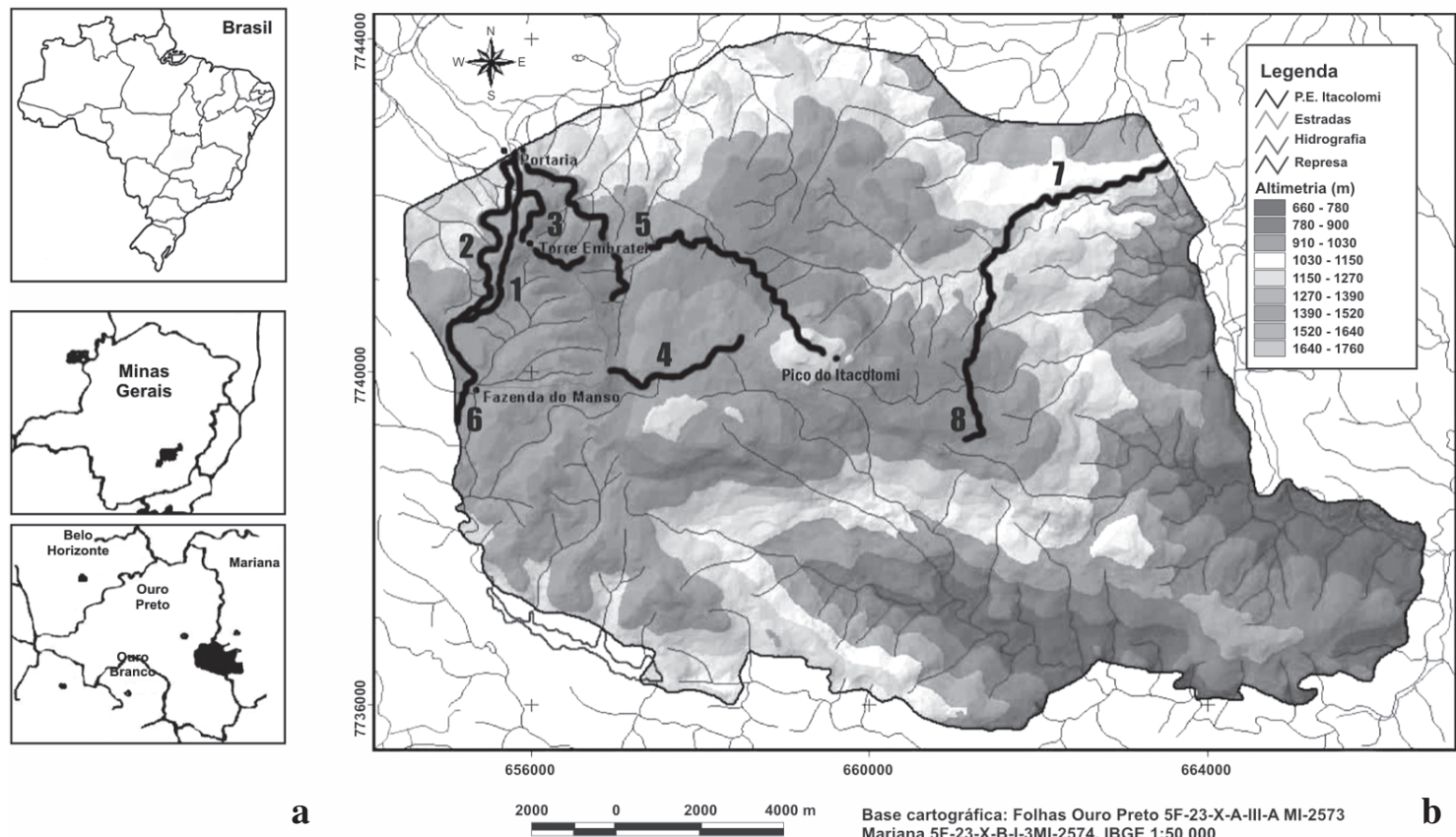

Figura 1 - a. Localização do Parque Estadual do Itacolomi. b. Trilhas estudadas: 1. Estrada de Cima, 2. Estrada de Baixo, 3. Morro do Cachorro, 4. Baú, 5. Calais, 6. Tesoureiro, 7. Serrinha e 8. Sertão. 
básicos de formações vegetacionais, segundo Dutra et al. (2008b): 1. campos graminosos secos; 2. campos graminosos úmidos; 3. campos graminosos úmidos de altitude; 4. campos quartzíticos dos afloramentos rochosos; 5. campos ferruginosos e 6. escrubes.

As coletas de material botânico foram realizadas mensalmente, entre setembro/2003 a outubro/2004, ao longo de oito trilhas (Fig. 1b). O material coletado foi herborizado segundo técnicas usuais (Mori et al. 1989), identificado e depositado no Herbário VIC, com duplicatas enviadas aos Herbários OUPR e RB (siglas conforme Holmgren et al. 1990).

A nomenclatura morfológica segue Radford et al. (1974) e Polhill \& Raven (1981), e os tipos de frutos segue Barroso et al. (1999). As diagnoses genéricas basearam-se na variação do táxon, extraída da literatura, e as diagnoses específicas ou infra-específicas na amplitude de variações morfológicas observadas no material coletado no PEI. São fornecidos, após a descrição de cada táxon, comentários sobre a distribuição geográfica, obtida na literatura, a ocorrência das espécies nas trilhas percorridas, os limites taxonômicos específicos e a fenologia, observada mensalmente.

\section{Resultados e Discussão}

Mimosoideae está representada, nos campos rupestres do PEI, por 11 espécies, reunidas em três gêneros, Abarema, Inga e Mimosa. O gênero com maior riqueza foi Mimosa, com nove táxons e oito espécies, seguido por Inga, com duas espécies, e Abarema com apenas uma espécie. $\mathrm{O}$ gênero Mimosa também é o de maior destaque, da subfamília Mimosoideae, nos demais campos rupestres (Dutra et al. 2008a).

As espécies dessa subfamília, no PEI, podem ser identificadas pelo hábito arbustivo ou subarbustivo, ereto, prostrado ou escandente; folhas pinadas ou bipinadas; flores actinomorfas, gamossépalas e gamopétalas, com filetes alvos, amarelos ou róseos; e frutos do tipo legume, circinado ou nucóide, craspédio ou sacelo.

\section{Chave para os gêneros de Mimosoideae}

1. Folhas pinadas

1. Folhas bipinadas.

2. Nectários foliares presentes; fruto legume circinado

1. Abarema

2'. Nectários foliares ausentes; fruto craspédio 3. Mimosa

1. Abarema Pittier, Arb. Legum. 56.1927.

Arbustos ou árvores. Folhas bipinadas, pares de pina e foliólulos de um a muitos; estípulas decíduas; nectários foliares campanulados a cupuliformes, pateliformes, verruciformes ou raramente estipitados. Inflorescências espiciformes, racemosas ou capituliformes, axilares; flores pentâmeras, homomórficas ou heteromórficas; cálice campanulado ou turbinado-campanulado; corola funiliforme; estames 10-60, filetes alvos, unidos em um tubo menor ou maior que a corola, tubo aderente à corola formando uma curta estemonozona. Frutos do tipo legume, deiscência elástica, circinados formando espirais de uma ou mais voltas; sementes com pleurograma.
1.1 Abarema langsdorfii (Benth.) Barneby \& Grimes, Mem. New York Bot. Gard. 74(1): 95. 1996.

Fig. 2 a-c

Arbustos 2-4 m alt., ramos puberulentos. Folhas 10-12-pinadas; estípulas não observadas; raque foliar 8,3-13,5 cm compr., puberulenta; 32-40 foliólulos, 6-10 × 2-3 mm, oblongos, glabros, discolores; nectários foliares pateliformes, entre os pares distais dos foliólulos e das pinas. Inflorescências racemosas; flores 2,4-2,9 cm compr., homomórficas; cálice ca. 4 mm compr., campanulado, puberulento; corola 6-7 mm compr., infundibuliforme, puberulenta; estames 29-35, 1,2-2,6 cm compr., heterodínamos, filetes alvos, glabros, tubo estaminal ca. $6 \mathrm{~mm}$ compr.; ovário ca. $2 \mathrm{~mm}$ compr., seríceo, estilete $1,5-2,5 \mathrm{~cm}$ compr., glabro. Legumes 4,2-5,2 cm diâm., 9- 
10 mm larg., glabros; 7-9 sementes, 5-6 $\times 4$ $15 \mathrm{~mm}$ compr., ovaladas, bicolores, azulacinzentadas e brancas.

Material examinado: Parque Estadual do Itacolomi, Ouro Preto, Calais, 9.XII.2003, fl., V. F. Dutra et al. 149(OUPR, VIC); Mariana, Serrinha, 14.IV.2004, fl. e fr., V. F. Dutra \& F. C. P. Garcia 222 (OUPR, RB, VIC).

Árvore característica e exclusiva da zona da mata pluvial da encosta atlântica (Barneby \& Grimes 1996). Habita ambientes rochosos, locais abertos, capoeiras e capoeirões, sempre em elevações submontanas (Burkart 1979; Barneby \& Grimes 1996). Ocorre no PEI, em campos quartzíticos de afloramentos rochosos e campos graminóides úmidos, onde forma grande população. Floresceu e frutificou de dezembro a abril.

É uma espécie de fácil identificação devido aos racemos curtos e densos com flores, quase ou completamente, homomórficas, características que, segundo Barneby \& Grimes (1996), distinguem A. langsdorfii das demais espécies brasileiras de Abarema.

\section{Inga Mill., Gard. Dict. Abr. ed. 4. 1754.}

Arbustos ou árvores. Folhas pinadas, paripinadas, 2-22 folíolos; estípulas persistentes; raque em geral alada; nectários foliares presentes. Inflorescências racemosas, espiciformes ou umbeliformes; axilares ou raramente caulifloras; flores 5-meras, homomórficas; cálice tubular, campanulado ou inflado; corola actinomorfa, tubular a campanulada; estames 20-350; filetes alvos, creme ou róseos, monadelfos em tubo; gineceu unicarpelar ou pluricarpelar. Legumes nucóides, indeiscentes ou tardiamente deiscentes; sementes sem pleurograma, envoltas por sarcotesta branca carnosa.

\section{Chave para as espécies de Inga}

1. Estípulas 9-13 mm compr.; estípite dos nectários foliares 5-14 mm compr.; filetes alvos ...... 2.1. I. barbata

1'. Estípulas 3-5 mm compr.; estípite dos nectários foliares 1-2 mm compr.; filetes róseos 2.2. I. vulpina

2.1 Inga barbata Benth., London J. Bot. 4: 604-605. 1845.

Fig. 2 d-g

Arbustos ca. $3 \mathrm{~m}$ alt., ramos rufo-hirsutos. Folhas 6-8-folioladas; estípulas 9-13 × 3-5 mm compr., lanceoladas; raque foliar 9,5-12,5 cm compr., ferrugíneo-hirsuta, alada; folíolos 7-12,1 × 2,8-4,6 cm, elípticos a ovados, híspidos; nectários foliares estipitados, estípite 5-14 mm compr., entre todos os pares de folíolos. Inflorescências espiciformes, axilares; flores 3,2-4 cm compr.; cálice 5-6 mm compr., campanulado, hirsuto; corola 1,3-1,4 cm compr., campanulada, serícea; estames ca. 48 , 2,8-3,2 cm compr., heterodínamos, filetes alvos, glabros, tubo estaminal 1-1,2 cm compr.; ovário 1,5-2 mm compr., glabro, estilete $2-3 \mathrm{~cm}$ compr, glabro. Legumes $6,2-7 \times 3-3,3 \mathrm{~cm}$, hirsutos; ca. 4 sementes, $1,6-1,9 \times 0,8-0,9 \mathrm{~cm}$, oblongas, oliváceas.

Material examinado: Parque Estadual do Itacolomi, Mariana, Serrinha, 21.I.2004, fl. e fr., V. F. Dutra et al. 170 (OUPR, RB, VIC).
Ocorre em Minas Gerais, Rio de Janeiro, São Paulo e Paraná, em floresta ombrófila densa montana e em floresta estacional em meio a campos de altitude (Garcia 1998). No PEI, foi encontrada apenas em campos graminosos úmidos. Foi observado material florido e frutificado no mês de janeiro.

É uma espécie relacionada a I. vulpina Mart. ex Benth., diferindo pelo tamanho das estípulas e do estípite dos nectários foliares, tipo de indumento dos folíolos e coloração dos estames (Garcia 1998). A mesma autora citou como região de simpatria de I. barbata e I. vulpina, o Rio de Janeiro e São Paulo. O presente estudo acrescenta o PEI como área de simpatria.

2.2 Inga vulpina Mart. ex Benth., Trans. Linn. Soc. London 30(3): 625. $1875 . \quad$ Fig. $2 \mathrm{~h}-\mathrm{j}$ Arbustos 2,5-3 m alt., ramos castanhohirsutos. Folhas 6-8-folioladas; estípulas 3-5× 1-2 mm compr., lanceoladas; raque foliar 5,9- 


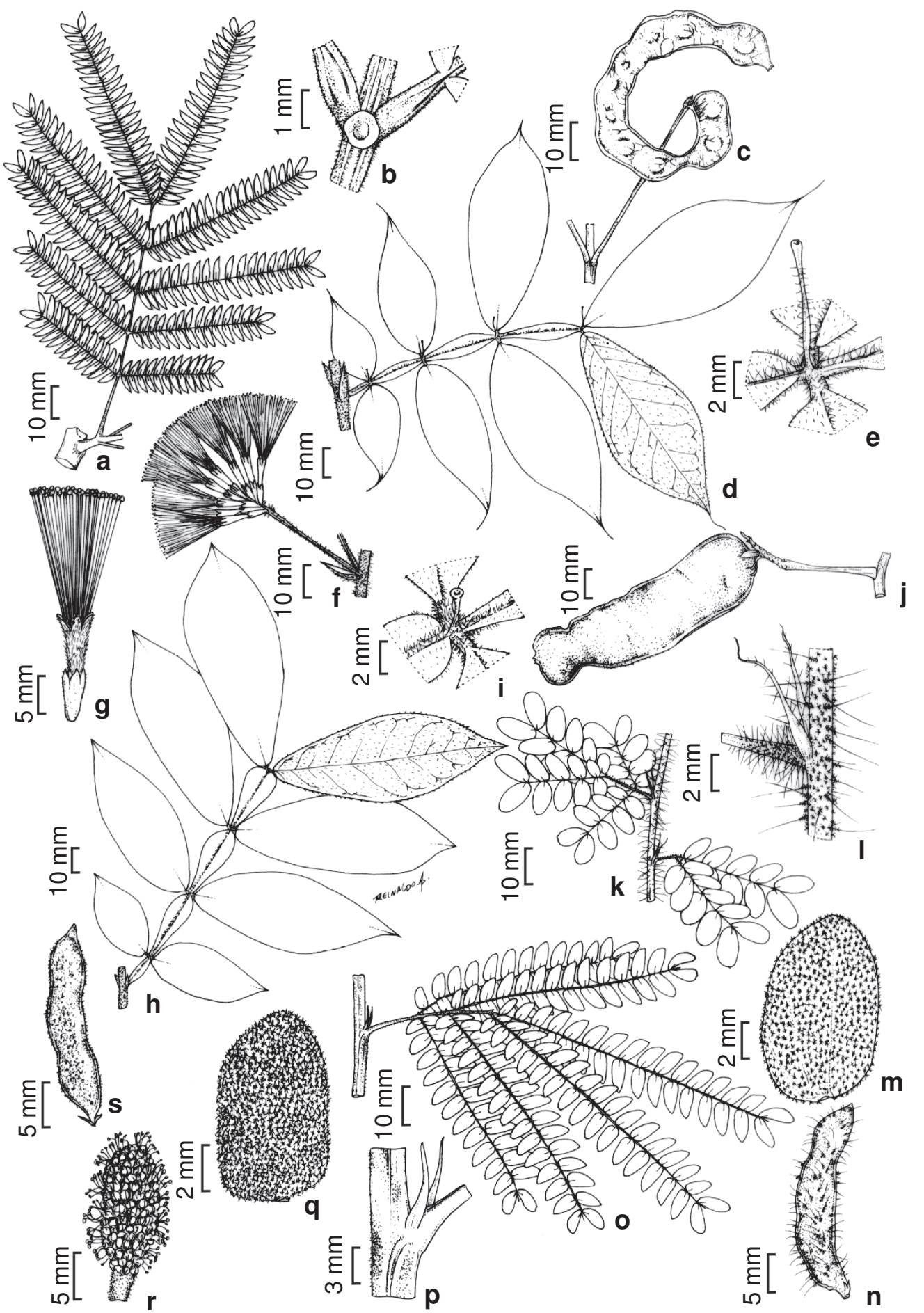

Figura 2 - Abarema langsdorfii - a. folha; b. nectário foliar; c. fruto; Inga barbata - d. folha e estípulas; e. nectário foliar; f. inflorescência; g. flor; I. vulpina - h. folha; i. nectário foliar; j. fruto; Mimosa aurivillus var. aurivillus - k. folhas; 1. estípulas; m. indumento da face abaxial do foliólulo; n. fruto; M. aurivillus var. calothamnos - o. folha; p. estípulas; q. indumento da face abaxial do foliólulo; r. inflorescência elipsóide; s. fruto (a-c Dutra 222; d-g Dutra 170; h-j Dutra 137; k-m Dutra 267; n Dutra 213; o-q Dutra 249; r Dutra 158; s Dutra 249). 
13,5 cm compr., hirsuta, alada; folíolos 5-14,5 $\times 2,7-5,3 \mathrm{~cm}$, elípticos, face abaxial hirsuta, face adaxial glabra; nectários foliares estipitados, estípite 1-2 mm compr., entre todos os pares de folíolos. Inflorescências espiciformes, axilares; flores ca. $3,5 \mathrm{~cm}$ compr.; cálice ca. $8 \mathrm{~mm}$ compr., campanulado, hirsuto; corola ca. 1,2 cm compr., campanulada, hirsuta; estames 40-45, 2-3,2 cm compr., heterodínamos, filetes róseos, glabros, tubo estaminal ca. 1,2 cm compr.; ovário ca. 2 mm compr., glabro, estilete ca. $2,8 \mathrm{~cm}$ compr., glabro. Legumes 6,4-9,8 $\times 2,4-2,7 \mathrm{~cm}$, hirsutos; 6-8 sementes, $1-1,2 \times 0,9-1,1 \mathrm{~cm}$, oblongas, negras. Material examinado: Parque Estadual do Itacolomi, Ouro Preto, Estrada de Cima, 30.IX.2003, fl., V. F. Dutra et al. 137(OUPR, RB, VIC); Calais, 20.I.2004, fr., V. F. Dutra et al. 167 (OUPR, RB, VIC).

Ocorre da Bahia a Santa Catarina, em especial em matas de altitude, acima de $400 \mathrm{~m}$, áreas de transição entre cerrado, campo cerrado e campo rupestre, sendo uma das poucas espécies de Inga a sobreviver em solos pedregosos dos campos rupestres e cerrados do estado de Minas
Gerais, suportando baixas temperaturas (Pennington 1997; Garcia 1998). Foi coletada no PEI em escrubes, sobre filito e quartzito, e sua ocorrência foi observada também em campos graminosos úmidos. Floresceu em setembro e frutificou de outubro a fevereiro.

\section{Mimosa L., Sp. Pl. 1: 516. 1753.}

Ervas, trepadeiras, subarbustos, arbustos ou árvores. Folhas bipinadas, pinas 1-muitos pares, primeiro par de foliólulos de cada pina comumente diferenciado em parafilídios; estípulas geralmente persistentes; nectários foliares ausentes. Inflorescências espiciformes ou capituliformes, axilares ou terminais; flores 3-5(-6)-meras, homomórficas ou heteromórficas; cálice campanulado, reduzido, denticulado ou lobado; corola campanulada ou tubulosa; androceu iso- ou diplostêmone, filetes róseos, purpúreos, alvos ou amarelo-claros ou brilhantes, livres ou unidos na base. Frutos craspédios ou sacelos; sementes com pleurograma.

1. Pinas $2-6$.

\section{Chave para as espécies de Mimosa}

2. Plantas armadas.

3. Pinas 4

3.7. M. pudica var. hispida

3'. Pinas 2.

4. Foliólulos 4, com 3,2-6,3 cm compr.

3.8. M. sensitiva var. malitiosa

4'. Foliólulos 24-30, com 1,2-2,1 cm compr. 3.3. M. dolens var. dolens

2'. Plantas inermes.

5. Raque foliar 4-25 mm compr.; filetes amarelos

3.1. M. aurivillus

5'. Raque foliar 1-2 mm compr.; filetes róseos.

6. Foliólulos 18-26, com 7-14 mm compr.

6'. Foliólulos 46-76, com 4-5 mm compr.

3.4. M. montis-carasae

1'. Pinas 8-14.

7. Raque foliar 2,5-3,5 cm compr.; foliólulos 3-4 mm compr.

3.2. M. diplotricha var. diplotricha

7'. Raque foliar 7,8-13,6 cm compr.; foliólulos 5,5-9 mm compr. .... 3.6. M. pigra var. pigra

3.1 Mimosa aurivillus Mart., Flora 21 (2, Beibl. 4-5): 52. 1838.

Arbustos 1,5-2 m alt., ramos hirsutos ou densamente tomentosos. Folhas 2-6-pinadas; estípulas 4-7 mm compr., lanceoladas ou filiformes, persistentes; raque foliar 4-25 mm, híspida ou densamente tomentosa; 8-30 foliólulos, 5-11×3-6 mm, oblongos, face abaxial flocosa ou não, revestida por tricomas estrelados, face adaxial glabra ou revestida por tricomas estrelados; parafilídios presentes. Inflorescências capituliformes, globosas ou elipsóides, axilares; flores 4-meras, 5-7 mm compr., homomórficas; cálice reduzido; corola $2-3 \mathrm{~mm}$ compr., 
tomentosa ou com tricomas estrelados; 4 estames, ca. $5 \mathrm{~mm}$ compr., homodínamos ou heterodínamos, filetes amarelos, glabros, tubo estaminal ca. $1 \mathrm{~mm}$ compr.; ovário ca. $1 \mathrm{~mm}$ compr., hirsuto ou tomentoso, estilete 4-5 mm compr., glabro. Craspédio 1-5-articulados, 1$2,4 \times 0,4-1,2 \mathrm{~cm}$, hirsutos ou flocosos; sementes 4-5 × 2-3 mm, ovadas, negras.

\section{Chave para as variedades de Mimosa aurivillus}

1. Ramos hirsutos; foliólulos 8-10, ambas as faces revestidas por tricomas estrelados 3.1.1. M. aurivillus var. aurivillus

1'. Ramos argenteo-tomentosos; foliólulos 24-30, face abaxial denso-tomentosa, face adaxial glabra 3.1.2. M. aurivillus var. calothamnos

3.1.1 Mimosa aurivillus Mart. var. aurivillus, Flora 21 (2, Beibl. 4-5): 52. 1838.

Fig. 2 k-n

Arbustos 1,5-1,6 $\mathrm{m}$ alt., ramos hirsutos. Folhas 2-4-pinadas; estípulas 6-8 × $1 \mathrm{~mm}$, lanceoladas; raque foliar $0,4-0,9 \mathrm{~cm}$ compr., híspida; 8-10 foliólulos, 8-11 × 4-6 mm, oblongos, tricomas estrelados em ambas as faces. Inflorescências globosas; flores 6-7 mm compr.; corola com tricomas estrelados; estames homodínamos, filetes amarelo-claros; ovário hirsuto, estilete ca. $5 \mathrm{~mm}$ compr. Craspédios 2-5-articulados, 1,6-2,4×0,4-1,2 $\mathrm{cm}$, hirsutos; sementes 4-5 ×2 mm.

Material examinado: Parque Estadual do Itacolomi, Ouro Preto, Tesoureiro, 13.IV.2004, fl. e fr., V. F. Dutra \& F. C. P. Garcia 213 (OUPR, RB, VIC); 18.VIII.2004, fl. efr., V. F Dutra \& L. C. P. Lima 267 (OUPR, RB, VIC).

Possui distribuição restrita à Cadeia do Espinhaço, ocorrendo associada a afloramentos rochosos, em campos rupestres, entre 1.100 1.900 m (Barneby 1991). No PEI, ocorreu sobre campo ferruginoso. Floresceu em abril, agosto e setembro, e frutificou de abril a agosto.

É caracterizada pelo tamanho da raque foliar, que é mais curta, e pelos tricomas estrelados, rígidos e em menor densidade, em ambas as faces dos foliólulos (Barneby 1991).

\subsubsection{Mimosa aurivillus var. calothamnos} (Benth.) Barneby, Mem. New York Bot. Gard. 65: 326. 1991.

Fig. 2 o-s

Arbustos 1,5-2 m alt., ramos densamente argenteo-tomentosos, com tricomas estrelados. Folhas 4-6-pinadas; estípulas 4-7 mm compr., filiformes; raque foliar $0,8-2,5 \mathrm{~cm}$ compr., denso-tomentosa; 24-30 foliólulos, 5-8 × 3-5 $\mathrm{mm}$, oblongos, face abaxial denso-tomentosa, com tricomas estrelados, face adaxial glabra. Inflorescências globosas ou elipsóides; flores 5-6 mm compr.; corola tomentosa; estames heterodínamos, filetes amarelo-brilhantes; ovário tomentoso, estilete ca. $4 \mathrm{~mm}$ compr. Craspédios 1-4-articulados, $1-2,3 \times 0,4-0,5 \mathrm{~cm}$, tomentosos; sementes $4 \times 3 \mathrm{~mm}$ compr.

Material examinado: Parque Estadual do Itacolomi, Ouro Preto, estrada de baixo, 14.IV.2004, fl., V. F. Dutra \& F. C. P. Garcia 225 (OUPR, RB, VIC); estrada de cima, 23.VI.2004, fr., V. F. Dutra \& L. C. P. Lima 249 (OUPR, RB, VIC); 23.VI.2004, fr., V. F. Dutra \& L. C. P. Lima 250 (VIC); Mariana, Serrinha, 10.XII.2003, fl., V. F. Dutra et al. 158 (VIC).

Apresenta distribuição descontínua ao longo da Cadeia do Espinhaço (MG), nas Serras da Mantiqueira (MG e RJ), dos Órgãos (RJ) e Bocaina (RJ e SP), habitando encostas pedregosas e locais abertos sobre afloramentos rochosos, em campos rupestres e campos de altitude (Barneby 1991). No PEI, é freqüente em escrubes sobre filito, em campos graminosos úmidos, em campos quartzíticos dos afloramentos rochosos e em campos ferruginosos, não apresentando, portanto, exigências quanto ao tipo de solo. Floresceu de setembro a abril e frutificou de dezembro a junho.

Diferencia-se das outras variedades pela raque foliar relativamente longa e pelos foliólulos mais numerosos e densamente cobertos por um indumento denso-tomentoso, de finos tricomas estrelados, que ocultam completamente a face abaxial (Barneby 1991). Assemelha-se $a M$. calodendron Mart. ex Benth., distinguindose desta pela raque foliar mais longa. 
3.2 Mimosa diplotricha C. Wright ex Sauvalle var. diplotricha, Anales Acad. Ci. Med. Habana 5: 405. 1868.

Fig. $3 a-b$

Subarbustos escandentes, ca. 1,5 m alt., ramos tomentosos, aculeados, acúleos recurvados. Folhas 12-14-pinadas; estípulas 5$6 \mathrm{~mm}$ compr., filiformes, persistentes; raque foliar 2,5-3,5 cm compr., hirsuta, aculeada; 2034 foliólulos 3-4 × $1 \mathrm{~mm}$, oblongo-lineares, esparsamente setosos; parafilídios presentes. Inflorescências capituliformes, globosas, axilares; flores 4-meras, 8-9 mm compr., heteromórficas, estaminadas na periferia, hermafroditas no centro da inflorescência; cálice 0,5-1 mm compr., campanulado, glabro; corola 1,5-2 mm, glabra; 8 estames, 7-8 mm compr., heterodínamos, filetes róseos, livres, glabros; ovário ca. $1 \mathrm{~mm}$ compr., glabro, estilete 5-6 mm compr., glabro. Frutos não observados.

Material examinado: Parque Estadual do Itacolomi, Ouro Preto, Estrada de Baixo, 22.I.2006, fl., V. F. Dutra \& G.S. S. Almeida 271 (VIC).

Distribui-se no México, América Central e América do Sul, ocorrendo, no Brasil, do Amazonas a Santa Catarina, em pastagens, matas perturbadas, bordas de matas e estradas e em cerrado (Barneby 1991). No PEI, foi coletada em escrubes sobre filito. Foi observado material florido em janeiro.

Apresenta grandes variações no tamanho, número de pinas e foliólulos e pubescência. Caracteriza-se pelo caule e raque armados de acúleos recurvados e pontiagudos (Barneby 1991).

3.3 Mimosa dolens Vell. var. dolens, Fl. Flumin. 11: pl. 34. 1836.

Fig. $3 \mathrm{c}-\mathrm{h}$

Arbustos ca. $2 \mathrm{~m}$ alt., ramos viscosos, puberulento-uncinados, aculeados, acúleos recurvados. Folhas 2-pinadas; estípulas 4-7 × 1 $\mathrm{mm}$ compr., lanceoladas, persistentes; raque foliar 1-2 mm compr.; 24-30 foliólulos, 1,2-2,1 $\times 0,5-$ $0,8 \mathrm{~cm}$, oblongos, face abaxial estrigosa a glabra, face adaxial glabra; parafilídios ausentes. Inflorescências capituliformes, globosas, axilares ou terminais; flores 4-meras, 7-11 mm compr., heteromórficas, a maioria isostêmones, algumas oligostêmones no ápice da inflorescência; cálice 1-2 mm compr., campanulado, glabro; corola $3-$
4 mm compr., puberulenta; 2-4 estames, 0,7-1 cm compr., heterodínamos, filetes róseos, livres, tomentosos; ovário ca. $1 \mathrm{~mm}$ compr., glabro, estilete ca. 1,1 cm compr., glabro. Craspédios 13-articulados, 7-8 $\times 4-5 \mathrm{~mm}$, estrigosos; sementes $3 \times 3 \mathrm{~mm}$ compr., ovadas, castanhas.

Material examinado: Parque Estadual do Itacolomi, Ouro Preto, estrada de baixo, 17.III.2004, fl. e fr., V. F. Dutra \& F. C. P. Garcia 195 (OUPR, RB, VIC); 14.IV.2004, fr., V. F. Dutra \& F. C. P. Garcia 226 (OUPR, RB, VIC).

Espécie comum na Cadeia do Espinhaço, Serras da Mantiqueira (MG e RJ) e do Mar (SP), ocorrendo até os estados de Goiás, Mato Grosso do Sul, Paraná e Distrito Federal, habitando cerrados e campos rupestres, em altitudes entre 700-1.700 m (Barneby 1991). No PEI ocorre em escrubes sobre filito. Floresceu em março e frutificou em março e abril.

Caracteriza-se por apresentar ambas as faces dos foliólulos e lobos da corola glabros ou puberulentos e frutos agrupados em uma estrutura globosa e compacta (Barneby 1991).

3.4 Mimosa montis-carasae Barneby, Mem. New York Bot. Gard. 65: 724. 1991.

Fig. 3 i-n

Arbustos 1-2m alt., ramos híspidos. Folhas 2-pinadas; estípulas 4-6 $\mathrm{mm}$ compr., lanceoladas, persistentes; raque foliar 1-2 mm compr.; 18-26 foliólulos, 7-14 × 3-5 mm, oblongo-lineares, seríceos; parafilídios presentes. Inflorescências capituliformes, globosas, axilares ou terminais; flores 4-meras, 0,8-1 cm compr., homomórficas; cálice menor que $1 \mathrm{~mm}$ compr., denticulado, glabro; corola ca. $3 \mathrm{~mm}$ compr., serícea; 4 estames, 7-9 mm compr., homodínamos, filetes róseos, livres, glabros; ovário ca. $1 \mathrm{~mm}$ compr., glabro, estilete ca. 1,1 cm compr., glabro. Sacelos 12-15 × 5-7 mm, híspidos; 2-4 sementes, $3 \times$ 2-3 mm, ovadas, marrons.

Material examinado: Parque Estadual do Itacolomi, Ouro Preto, estrada de baixo, 22.I.2004, fl., V. F. Dutra et al. 171 (OUPR, RB, VIC); 18.III.2004, fr., V. F. Dutra \& F. C. P. Garcia 194 (OUPR, RB, VIC); estrada de cima, 26.VI.2004, fr., V. F. Dutra \& L. C. P. Lima 247 (VIC); 26.VI.2004, fr., V. F. Dutra \& L. C. P. Lima 248 (VIC); proximidades da entrada do Parque, 15.I.1994, fl., M. B. Roschel \& S. L. Dias s.n. (OUPR 1452); estrada 

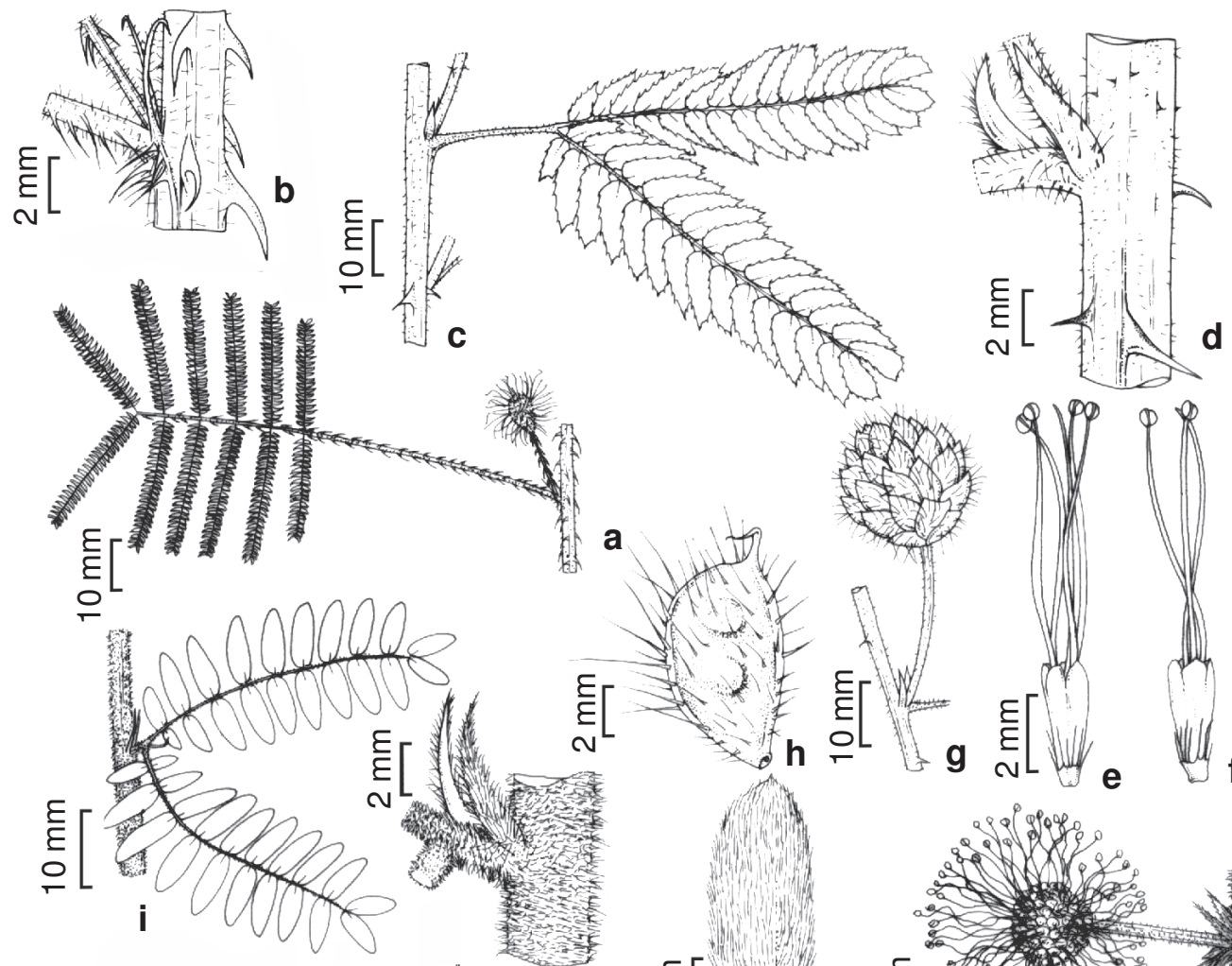

a
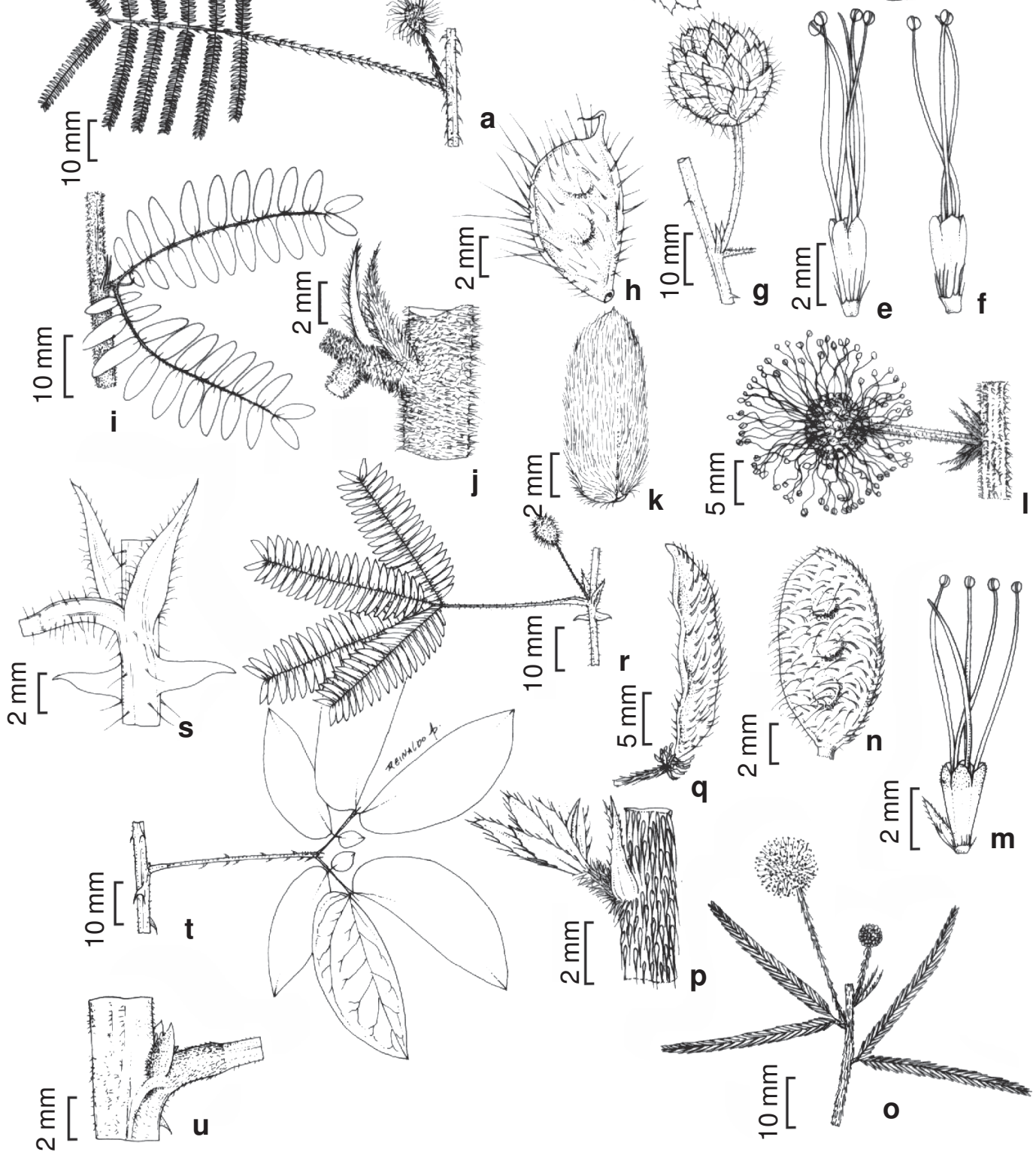

Figuras 3-Mimosa diplotricha var. diplotricha - a. ramo; b. estípulas e acúleos; M. dolens var. dolens - c. folha; d. estípulas e acúleos; e. flores isostêmones; f. flores oligostêmones; g. frutos de uma inflorescência; h. fruto; M. montis-carasae-i. folha; j. estípulas; k. indumento da face abaxial do foliólulo; 1 inflorescência globosa; $\mathrm{m}$. flor; $\mathrm{n}$. fruto; $M$. ourobrancoënsis - o. ramo; p. estípulas e indumento do caule e do pecíolo; q. fruto; $M$. pudica var. hispida-r. ramo; s. estípulas e acúleos; $M$. sensitiva var. malitiosa - t. folha; u. estípulas (a-b Dutra 271; c-f Dutra 195; g-h Dutra 226; i-m Dutra 171; n Dutra 247; o-q Dutra 268; r-s Dutra 270; t-u Almeida s.n. VIC 30738). 
para o Manso, 12.XII.1990, fl., H. C. Lima et al. 4071 (OUPR, RB).

Segundo Barneby (1991) Mimosa montiscarasae seria restrita à Serra do Caraça, Minas Gerais, no entanto, neste trabalho, ampliamos sua área de ocorrência. No PEI, ocorre grandes populações em áreas de escrube sobre filito. Floresceu de novembro a fevereiro e frutificou de março a junho.

Possui maior afinidade a $M$. pogocephala Benth., da qual difere pelo indumento híspido do caule, pinas menores, com número menor de foliólulos seríceos e frutos híspidos (Barneby 1991).

Encontra-se na categoria Em Perigo segundo a lista vermelha das espécies ameaçadas de extinção do estado de Minas Gerais (Mendonça \& Lins 2000).

\subsection{Mimosa ourobrancö̈nsis Burkart,} Darwiniana 7: 537. 1947.

Fig. 3 o-q

Arbustos ca. $60 \mathrm{~cm}$ alt., ramos retroestrigosos. Folhas 2-pinadas; estípulas 3-4 × 1 mm compr., lanceoladas, persistentes; raque foliar ca. $1 \mathrm{~mm}$ compr.; 46-76 foliólulos, 4-5×1 mm, lanceolados, glabros; parafilídios presentes. Inflorescências capituliformes, globosas, axilares; flores 4-meras, 8-9 mm compr., heteromórficas, estaminadas na periferia, hermafroditas no centro da inflorescência; cálice ca. $1 \mathrm{~mm}$ compr., denticulado, glabro; corola ca. 2-3 mm compr., puberulenta; 4 estames, 6-7 mm compr., homodínamos, filetes róseos, livres, glabros; ovário ca. $1 \mathrm{~mm}$ compr., glabro, estilete 5-6 mm compr., glabro. Craspédios 3-4-articulados, 2$2,6 \times 0,3-0,4 \mathrm{~cm}$, estrigosos; sementes, $4 \times 2$ mm, ovadas, negras.

Material examinado: Parque Estadual do Itacolomi, Ouro Preto, 1.XI.1996, fl., M. C. T. B. Messias s.n. (VIC 28468); estrada para Fazenda do Manso, 11.XI.1996, fl., M. C. T. B. Messias s.n. (VIC 28467); estrada de cima, 20.IX.2004, fl. e fr., V. F. Dutra et al. 268 (OUPR, RB, VIC).

Material adicional examinado: BRASIL. MINAS GERAIS: Serra de Ibitipoca, 5.V.1952, fl., L. Krieger 1879 (RB); 30.IX.1970, fl., D. Sucre 7211 (RB).

Citada por Barneby (1991) para a região de Ouro Branco, porção sul da Cadeia do Espinhaço (MG) e para a Serra de Itatiaia (RJ). Ocorre também na Serra de Ibitipoca, região da Serra da Mantiqueira (MG). Nos campos rupestres, habita pequenas áreas em altitudes acima de 1.000 m (Barneby 1991). No PEI foi encontrada apenas em vegetação de escrube sobre filito. Floresceu em setembro e frutificou em setembro e outubro.

Mimosa ourobrancoënsis é facilmente reconhecida pelo seu hábito, que consiste em um arbusto delgado e pouco ramificado, pelo indumento denso e retro-estrigoso e por apresentar apenas um par de pinas, relativamente longas e estreitas, pluri-folioluladas (Barneby 1991). Através da análise do material herborizado verificou-se que a espécie citada por Messias et al. (1997), no levantamento florístico do Parque, como Mimosa densa Benth. trata-se de Mimosa ourobrancoënsis.

3.6 Mimosa pigra L. var. dehiscens (Barneby) Glazier \& Mackinder, Kew Bull. 52(2): 462.1997.

Arbustos ca. $2 \mathrm{~m}$ alt., ramos estrigosos, aculeados, acúleos recurvados. Folhas 8-12pinadas; estípulas 4-5 × $1 \mathrm{~mm}$, lanceoladas, persistentes; raque foliar 7,8-13,6 cm compr., estrigosa; 30-68 foliólulos, 5,5-9×1 mm, oblongolineares, glabros; parafilídios presentes. Inflorescências capituliformes, globosas, axilares; flores 4-meras, 3-6 mm compr., heteromórficas, estaminadas na periferia, hermafroditas no centro da inflorescência; cálice ca. $1 \mathrm{~mm}$ compr., campanulado, glabro; corola 2-3 mm, estrigosa; 8 estames, ca. $3 \mathrm{~mm}$ compr., homodínamos, filetes róseos, livres, glabros; ovário ca. 1 mm compr., seríceo, estilete ca. $1 \mathrm{~mm}$ compr. Craspédios 12-18-articulados, $6,5-8,7 \times 1,1-1,2 \mathrm{~cm}$, estrigosos; sementes 5 $\times$ 2-3 mm, oblongo-elípticas, oliváceas.

Material examinado: Parque Estadual do Itacolomi, Mariana, Serrinha, 10.XII.2003, fl. efr., V. F. Dutra et al. 160 (VIC); 14.IV.2004, fl. e fr., V. F. Dutra \& F. C. P. Garcia 221 (VIC).

Ocorre na Bolívia, Paraguai e Brasil, em áreas de campo e campo cerrado (Barneby 1991; Glazier \& Mackinder 1997). Apesar da ampla distribuição, no PEI foi encontrada apenas uma população em campos graminosos úmidos. Floresceu e frutificou de dezembro a abril. 
Distingue-se pelo indumento densoestrigoso do caule e pelas folhas multifolioladas (Woodson \& Schery 1950). Além disso, apresenta a corola estrigosa e os acúleos são recurvados (Barneby 1991).

\subsection{Mimosa pudica var. hispida Brenan, Kew} Bull. 10(2): 186-187. 1955.

Fig. 3 r-s

Subarbustos prostrados, ramos híspidos, aculeados, acúleos recurvados. Folhas 4-pinadas; estípulas 6-8 8 1-2 mm, lanceoladas, persistentes; raque foliar 1-2 mm compr., híspidas; 30-42 foliólulos, 8-10 × 1,5-2 mm, oblongo-lineares, glabros; parafilídios presentes. Inflorescências capituliformes, espiciformes, axilares; flores 4meras, 7-9 mm compr., homomórficas; cálice menos que $1 \mathrm{~mm}$ compr., campanulado, glabro; corola ca. $2 \mathrm{~mm}$, tomentosa; 4 estames, $6-8 \mathrm{~mm}$ compr., homodínamos, filetes róseos, livres, puberulentos; ovário ca. $1 \mathrm{~mm}$ compr., tomentoso, estilete ca. $5 \mathrm{~mm}$ compr., glabro. Craspédios $3-$ 4-articulados, 1,1-1,6 $\times 0,4-0,5 \mathrm{~cm}$, estrigosos; sementes $2 \times 1 \mathrm{~mm}$, elípticas, negras.

Material examinado: Parque Estadual do Itacolomi, Mariana, Serrinha, 20.I.2006, fl. e fr., V. F. Dutra \& G. S. S. Almeida 270 (VIC).

Distribui-se nas Américas, na África equatorial, Índia, Filipinas, Bornéo e Java (Barneby 1991). No Brasil ocorre ao longo da costa atlântica e em regiões com altitudes superiores a $1.500 \mathrm{~m}$, de Minas Gerais a Santa Catarina (Barneby 1991). No PEI, foi coletada em campos graminosos úmidos. Foi observado material florido e frutificado em janeiro.

Mimosa pudica var. hispida distingue-se de $M$. pudica var. unijuga, M. pudica var. tetranda e M. pudica var. pastoris principalmente pelo indumento característico do caule, com longos tricomas híspidos (Barneby 1991).

3.8 Mimosa sensitiva var. malitiosa (Mart.) Barneby, Brittonia 37(2): 153. 1985.

Fig. $3 \mathrm{t}-\mathrm{u}$

Arbustos escandentes, ramos retroestrigosos, aculeados, acúleos recurvados. Folhas 2-pinadas; estípulas $4-5 \times 1 \mathrm{~mm}$, lanceoladas, persistentes; raque foliar ausente; 4 foliólulos, 3,2-6,3 $\times 0,8-2,3 \mathrm{~cm}$, falcados, face abaxial estrigosa, face adaxial glabra; parafilídios presentes. Inflorescências capituliformes, globosas, axilares; flores 4-meras, ca. $1 \mathrm{~cm}$ compr., homomórficas; cálice $2-3 \mathrm{~mm}$ compr., campanulado, glabro; corola 2-3 mm, setosa; 4 estames, 2-2,3 cm compr., homodínamos, filetes róseos, livres, glabros; ovário 0,5-1 mm compr., glabro, estilete $8-9 \mathrm{~mm}$ compr., glabro. Frutos não observados.

Material examinado: Parque Estadual do Itacolomi, Ouro Preto, Morro do Cachorro, III.2006, fl., G. S. S. Almeida s.n. (VIC 30738).

Planta invasora, amplamente distribuída na América Tropical (Queiroz 2004). No Brasil, ocorre em São Paulo, Bahia, norte e sul de Minas Gerais e ao longo da Cadeia do Espinhaço, em beiras de estradas e áreas perturbadas (Barneby 1991). Foi coletada no PEI em escrube sobre filito. Floresceu de janeiro a março.

Mimosa sensitiva var. malitiosa possui íntima relação com M. velloziana Mart., que difere, principalmente pelo cálice diminuto e foliólulos glabros (Barneby 1991). Distingue-se de $M$. sensitiva $L$. var. sensitiva pelas brácteas e capítulos menores (Barneby 1991).

\section{Considerações Finais}

Os campos rupestres do PEI apresentaram baixa similaridade florística de Mimosoideae com Grão-Mogol (Queiroz 2004), sendo comum a essas áreas apenas Mimosa sensitiva var. malitiosa. O contrário ocorre com a Serra de Ouro Branco (Dutra et al. 2008), pois as quatro espécies encontradas, nesta serra, também ocorrem no PEI.

Das 11 espécies encontradas no PEI, apenas Mimosa aurivillus já havia sido citada para a flora do Parque por Peron (1989) e Messias et al. (1997); e M. aurivillus var. aurivillus e M. montis-carasae são endêmicas da Cadeia do Espinhaço.

Ocorrem em populações pequenas e/ou restritas a hábitats específicos: Inga barbata, Mimosa aurivillus var. aurivillus, M. dolens var. dolens, M. montis-carasae e $M$. ourobrancoënsis, indicando a importância da preservação desses ambientes.

As duas variedades de Mimosa aurivillus 
podem ser indicadas para a recuperação de áreas degradadas pela atividade mineradora, pois são táxons bem sucedidos nos campos ferruginosos, ambientes que apresentam condições abióticas análogas a essas áreas.

\section{Agradecimentos}

Ao Instituto Estadual de Florestas (IEF), em nome do Eng. Alberto Vieira de Mello Matos, Diretor do Parque Estadual do Itacolomi, pela estrutura física e licença concedidas; aos funcionários do PEI e ao Jorge Luiz Silva, pelo auxílio nas coletas; aos curadores dos Herbários OUPR, RB e HUEFS; e a Reinaldo Pinto, pela elaboração das ilustrações.

\section{REFERÊNCIAS BIBLIOGRÁFICAS}

Barneby, R. C. 1991. Sensitivae censitae: a description of the genus Mimosa Linnaeus (Mimosaceae) in the New World. Memoirs of the New York Botanical Garden 65: 1-835.

\& Grimes, J. 1996. Silk tree, Guanacaste, Monkey's earring: a generic system for the synandrous Mimosaceae of the Americas. Memoirs of the New York Botanical Garden 74: 1-292.

Barroso, G. M.; Morim, M. P.; Peixoto, A. L. \& Ichaso, C. L. F. 1999. Frutos e sementes: morfologia aplicada à sistemática de dicotiledôneas. Imprensa Universitária, Viçosa, 443p.

; Peixoto, A. L.; Costa, C. G., Ichasso; C. L. F., Guimarães; E. F. \& Lima, H. C. 1991. Sistemática das Angiospermas do Brasil, vol. 2. Imprensa Universitária, Viçosa, 377p.

Benites, V. M.; Caiafa, A. N.; Mendonça, E. S.; Schaefer, C. E. \& Ker, J. C. 2003. Solos e vegetação nos complexos rupestres de altitude da Mantiqueira e do Espinhaço. Floresta e Ambiente 10: 76-85.

Bentham, G. 1876. Mimosaceae. In: Martius, C. F. P. von; Endlicher, S. \& Urban, I. (eds.). Flora brasiliensis. Monachii, Lipsiae, 15(1): 258-527.
Burkart, A. 1979. Flora Ilustrada Catarinense. Leguminosas Mimosoideas. Imprensa Oficial do estado de Santa Catarina S.A., Florianópolis, 299p.

Doyle, J. J.; Chappill, J. A.; Bailey, C. D. \& Kajita, T. 2000. Towards a comprehensive phylogeny of Legumes: evidence from $r b c \mathrm{~L}$ sequences and non-molecular data. In: Herendeen, P. S. \& Bruneae, A. (eds.). Advances in legume systematics 9. Royal Botanic Gardens, Kew. Pp.1-20.

Dutra, V. F.; Filardi, F. L. R. \& Garcia, F. C. P. 2008. Flora da Serra do Ouro Branco: Leguminosae Adans. In: Paula, C. C. (ed.). Flora da Serra de Ouro Branco. Vol. 1. 200p. ; Garcia, F. C. P.; Lima, H. C. \& Queiroz, L. P. 2008a. Diversidade Florística de Leguminosae Adans. em áreas de Campos Rupestres. Megadiversidade (Belo Horizonte) 4: 163-171.

; Garcia, F. C. P. \& Lima, H. C. 2008b. Caesalpinioideae (Leguminosae) nos Campos Rupestres do Parque Estadual do Itacolomi, Estado de Minas Gerais, Brasil. Acta Botanica Brasilica 22(2): 543-554.

Elias, T. S. 1981. Mimosoideae. In: Polhill, R. M. \& Raven, P. H. (eds.). Advances in legume systematics I. Royal Botanic Gardens, Kew. Pp.143-151.

Garcia, F. C. P. 1998. Relações sistemáticas e fitogeografia do gênero Inga Miller (Leguminosae, Mimosoideae, Ingeae) nas florestas da costa sul e sudeste do Brasil. Tese de doutorado, Universidade Estadual Paulista, Rio Claro, 248p.

Giulietti, A. M.; Pirani, J. R. \& Harley, R. M. 1997. Espinhaço Range region, Eastern Brazil. In: Davis, S. D. et al. (eds.). Centres of plants diversity 3. Information Press, Oxford. Pp. 397-404.

Glazier, D. \& Mackinder, B. A. 1997. Nomenclatural notes on South American Mimosa (Leguminosae-Mimosoideae). Kew Bulletin 52(2): 459-463.

Harley, R. M. 1995. Introduction. In: Stannard, B. L. (ed.). Flora of the Pico das Almas, Chapada Diamantina, Bahia, Brazil. Royal 
Botanical Gardens, Kew. Pp.1-40.

Holmgren, P. K.; Holmgren, N. H. \& Barnet, L. C. 1990. Index Herbariorum, ed 8, Part I. The herbaria of the world. The New York Botanical Garden Press, New York, 704p.

Lewis, G. P.; Schrire, B. D.; Mackinder, B. A. \& Lock, J. M. 2005. Legumes of the world. Royal Botanic Gardens, Kew, 592p.

Lima, L. C. P.; Garcia, F. C. P. \& Sartori, A. L. B. 2007. Leguminosae nas florestas estacionais do Parque Estadual do Itacolomi, Minas Gerais, Brasil: ervas, arbustos, subarbustos, lianas e trepadeiras. Rodriguésia 58(2): 331-358.

Mendonça, M. P. \& Lins, L. V. 2000. Lista Vermelha das espécies ameaçadas de extinção da flora de Minas Gerais. Fundação Biodiversitas, Fundação Zoobotânica de Belo Horizonte, Belo Horizonte, 157p.

Messias, M. C. T. B.; Dias, S. J.; Roschel, M. B.; Sousa, H. C. \& Matos, A. M. 1997. Levantamento florístico das matas e distribuição de algumas espécies endêmicas da área do Parque Estadual do Itacolomi. Relatório Técnico, UFOP/BIRD/IEFPROFLORESTA, 151p.

Mori, S. A.; Silva L. A. M.; Lisboa, G. \& Coradin, L. 1989. Manual de Manejo do Herbário Fanerogâmico. Centro de Pesquisas do Cacau, Ilhéus, 104p.

Nunes, S. R. D. F. S. 2003. As Mimosoideae (Leguminosae) no Parque Estadual do Rio Doce. Dissertação de Mestrado,
Universidade Federal de Viçosa, Viçosa, 106p.

Pennington, T. D. 1997. The genus Inga: Botany. Royal Botanic Gardens, Kew, 844p.

Peron, M. V. 1989. Listagem preliminar da flora fanerogâmica dos Campos Rupestres do Parque Estadual do Itacolomi, Ouro Preto/Mariana, MG. Rodriguésia 41(67): 63-69.

Pires, J. M. \& Prance, G. T. 1985. The vegetation types of the Brazilian Amazon. In: Prance, G. T. \& Lovejoy, T. E. (eds.). Key Environments: Amazonia. Pergamon Press Ltd., Oxford. Pp.136-138.

Polhill, R. M. \& Raven, P. H. 1981. Advances in Legume Systematics I. Royal Botanic Gardens, Kew, 425p.

Queiroz, L. P. 2004. Flora de Grão-Mogol, Minas Gerais: Leguminosae. Boletim de Botânica da Universidade de São Paulo 22: 213-265.

Radford, A. E.; Dickison, W. C.; Massey, J. R. \& Bell, C. R. 1974. Vascular plant systematics. Harper \& Row, New York, 891p.

Romero, R. 2002. Diversidade da flora dos Campos Rupestres de Goiás, Sudoeste e Sul de Minas Gerais. In: Araújo, E. L.; Moura, A. N.; Sampaio, E. V. S. B.; Gestinari, L. M. S. \& Carneiro, J. M. T. (eds.). Biodiversidade, conservação e uso sustentável da flora do Brasil Editora Universidade Federal de Pernambuco, Recife. Pp. 81-86. 